\title{
2. ARTISTIC PERSONALITY IN THE LIGHT OF SOCIO - CULTURAL INTEGRATION
}

Marinela Rusu ${ }^{282}$

\begin{abstract}
Artistic personality was interpreted in various ways through the ages. The power of creativity, individual perseverance and imaginative force made the artist a special person, different from most people, being equipped with unique, unrepeatable skills. This paper presents some of the most important approaches to the personality of the creator, from the questionable Freudian theory to the psycho-biological approaches of Peckham. Through his works, the artist expresses not only his personal anxieties or emotional ardent feelings but also, reflects a conscious level of the social group, being himself adapted to human values, characteristic of the era and society to which he belongs. Maybe, sometimes, wrong regarded as deviant personalities or too much exposed to excesses, artists remain, undoubtedly, brave in Creativity, in the cultural and social original development process. Their integration in this ensemble completes the picture we have about development and social evolution, and gives us access to more elevated human values.
\end{abstract}

Key words: artist, culture, society, social development, creativity

\section{Cultural differences in creativity}

A pertinent question is that if some societies really stimulates creativity and if creative personalities and artistic productivity and/or innovation are higher in some societies than in others. At first glance, these differences seem too obvious to be discussed and the only question is which are the factors that stimulate creative personalities? If we go further considerations or exploring ethnographic elements, we see they make us ask questions on this subject, and our assessment is based so much on ethnocentric selection of what is art and creativity. It is very possible that there is a similar proportion of aesthetic and creative capital in any society, but it is coordinated by the circumstances offered by life and cultural interpretation, in ways that we do not generally consider art or that there are ephemeral forms over which we have not still a registered statistics. The general opinion is that: "The amount of creative expression that is permitted or expected may differ from one society to another, from one period to another, from one craft to another, from one genre to another, and even from one part of a carving to another" (Bascom 1969, p. 111). It is accepted the idea that some people are born with a special talent for artistic creation and at the other extreme is the idea that anyone can become an artist, because in each of us there is the latent creative potential.

Anthropological interrogations were dealing with those aspects of culture that promote and discourages creativity or innovation. Example of Bali country is very interesting from this point of view, because it believes that a person "is an artist", even if it has a conservative civilization in which innovation is not the rule. Based on her experiences in Bali and in other cultures, Margaret Mead $(1935,1940$ and 1959) offers some hypotheses on one of the important factors

\footnotetext{
${ }^{282}$ Researcher PhD, Romanian Academy, Institute "Gh. Zane" from Iași Branch of Romania, email: marinela1808@yahoo.com
} 
that seems to promote creativity. It is "a symbolic development experience" that occurs early in a child's life, the formalization of roles and statuses in which the child is placed successively before being integrated into larger groups of children.

When this kind of experience is combined with exposure to more symbolically valued activities from an early age, he begins to manipulate and combine creatively many symbolic elements which are at his disposal. Some descriptions include Bali culture tend to use symbolic artistic situations so much that they seem a kind of escapism for a viewer from the outside. Other theories correlate the degree of creativity with social or psychological factors. Who is an artist? The definition of an artist can be: an artisan, man or woman, who, through a creative recombination and/or innovation make an artifact (tangible or intangible, i.e., a statue or a song) that reflects a high aesthetic component. This will include the ability to influence others in this kind of production. Such a definition is widespread, and this suggests the intercultural significance of this concept.

Who were the artists whose efforts were regarded as special in their own society and how were they identified? Two complementary questions can be put in this situation: How to reconcile the perspective of primitive societies in which "every man is an artist" or that in society artists "select themselves", with the idea that some crafts are made only for certain classes or people? What chance has a creative person to become an artist in these societies that prescribe exactly who will practice some artistic pursuits? Being nominated by birth in a particular social class or being successful in the creativity comes in clear contradiction with the idea that anyone can be an artist. But the choice limitation is only a limit of conditions. Many artists, even in our society, highly specialized, choose if his work is just for daily use or a work of art with obvious aesthetic traits, to which undertook with devotion.

The element of motivation, the opportunity to learn the craft and the recognition of this ability by other members of society are highlighted in the case of Àbátàn, a sculptor-clay female (African village, Yoruba), whose life was studied by D. Thompson (1969). Àbátàn is considered a master of sculpture in clay, ceramics and poetry. In her youth, she manifested as a dancer. Mother and grandmother were also creating ceramics and Àbátàn learned it from her mother in childhood. It was not a formal instruction, but only through the help and observation, she gradually learned the craft. At age 12, she had become expert of technological process of creating ceramic pots with practical use in household. Only at her 30 years was given the opportunity to create dishes with ritualistic figures, considered of sacred importance in the community. The talent shown in making them, made her achieve the fame as an artist and also achieve the appreciation of the community.

In societies with direct technologies the most common situation is where the basic skills of the trade are well known to all (for women or men), but only a fraction of them make the effort to learn to use these skills in a more creative way. Davenport (1968) writes about the inhabitants of the Western Solomons: 
"Who becomes a carver in the Western Solomons is determined mostly by interest and aptitude. There are neither hereditary positions for artists nor hereditary groups of artisans. Any male who has an interest and ability may become a sculptor. All men in this society are skilled wood workers and carvers, and are not necessarily better than ordinary craftsmen in the use of their tools. All men, too, are familiar with the traditional motifs and designs used in carving. High interest, then, is the first prerequisite for becoming a carver. Beyond this, the necessary talents are the same indefinable aesthetic characteristics that seem to distinguish the artist from the non-artist in our society" ${ }^{283}$.

\section{Personality}

When we speak of personality come to our mind several questions. One is related to artistic temperament, as manifested by artists in general, and how different they are from others in society. Another interrogation discusses his reporting on personality type promoted by a particular society in a particular historical epoch. Considering that art is a form of self-expression, a projection of the individual's emotional inner universe, otherwise called and personality, then we talk of a similarity of manufactures, which are part of a certain style. Accepting this definition, we say that a certain cultural style crystallized because of similarities of personalities in that society members, a "national character" or "modal personality" shared alike by artists and members of the community.

Ethnographic writings about the personal qualities of artists conforming to the rules of art produced by one community, gives us an image of consistency on both, as Margaret Mead describes in her book "Sex and Temperament" (1935). She describes the Sepik River communities, which share many cultural similarities, though they have very different male and female personality types. Given that modal personality and artistic projection theories are considered incomplete and inadequate explanations, this approach provides us sufficient reasoning and even opportunities to reformulate issues of culture and personality.

Often, we think, on an intuitive level, that portraits and pictures created by an artist, are expressing something about ourselves and that's why, many analysts used human art images to exemplify certain styles of creation. Some people's views on the world and life are reflected in their approach of what it would mean to be a human being, which is found in the basic couple, Adam and Eve, as individuals ideas about world are found in creation myths.

Self-images are multiple and include the general image about fear, images about someone's dreams and about someone's roles. Knowing something about the life of people experiencing these pictures and seeing the variety of forms they produce, we can better interpret this "self" which is revealed. Sometimes, the facial expression of anthropomorphic image communicate to viewer a feeling, an emotion of quality that are assigned to the creator. For example, faces and masks Navajo Hopi usually have a quality remote-controlled, very different from the dramatic intensity of the Kwakiutl masks. However, masks through

${ }^{283}$ Davenport 1968, p. 400 
their specific present the persona, so diverse and complex that, we can hardly expect someone to understand the dozens of senses and meanings given, without knowing the drama which they have been subjected and how these emotions are interpreted by onlookers. So, it is necessary to know the "scenario" of the presented characters, to have an idea of how people perceive the role of personality in artistic expression.

A direct effect of art on the personality is that it includes and gives examples of how people should have to react or not in special situations. Dramatic artwork, different dances, cartoons, all mimic reprehensible behaviors, be it as general reference or as a clear indication to certain historical characters. Art enhances, that the social model must be followed, and shows how a human being should behave in society. We recognize here, the modeling and training role of art on personality. It helps the individual to recognize his place in society and help him in the process of self-discovery. The social model offered is often positively appreciated and often, followed by those who know it.

\section{Artistic personality}

The paradox of seeing artists as a deviant gender of personality and in the same time, assuming that artist's projections reflects the modal personalities of culture, it finally appear to not necessarily be paradoxical if we review this report in other terms also. It seems that in all societies there are certain personality types that provide specialists, even there where the division of labor is not formalized yet. Mystic, skeptic, politician, artist, philosopher, practical person and the administration seem to be found as different types or predilections combined, which are often accepted as roles in society. Meanwhile, as stated M. Mead (1935), some personality types or trends are favored, while others are devalued in the structures of some societies, so that the observer has a strong feeling of being in front of a characteristic trait or, in other words, in front of a modal personality. ${ }^{284}$

If we think of the artist as a person who believes that the aesthetic can become a symbolic solution of problems and conflicts in a way that communicates it to others, we see how its "unusual" respond to the situation can express what others feel, too. An artist can, indeed, be a person who is particularly sensitive to the problem of contradictions in society, culture, and from this point of view, he/she expresses the "gender-anxiety". If his artistic solutions are consistent with the other's, his work will be accepted as art, not just as a personal aberration and thus we can say about them, that are the characteristic kind of solutions that fit the cultural type. The extent to which innovative efforts, separate from the creative, are valued, will depend on the need felt to find new solutions.

\footnotetext{
${ }^{284}$ The concept of modal personality was suggested by Cora DuBois, an early ethnographer trained in psychological methods, in her book The People of Alor (1944). Modal personality assumes that a certain personality structure is the most frequently occurring structure within a society, but this does not necessarily mean that the structure is common to all members of that society. This approach utilizes projective tests in addition to life histories to create a stronger basis for personality types due to the use of statistics to back up the conclusions (Spencer \& Jessie, J. - 1977).
} 
When we ask whether there exists interculturalism, an artistic temperament or artistic personality, actually we ask if there is a correlation between the degree of creativity and artistic interests in the work of a craftsman, and his conduct in any way. If we speak of a process of self-selection of artists, of course, it must be validated by the recognition of becoming a role, it suggests that there is some kind of configuration features of the artist's personality, in all societies and which integrates them on this path. Without making assumptions if these traits are the result of biological heredity, childhood experiences, divine intervention or a synthetic combination of all these factors, the comparison between artists from different cultural structures suggests certain regularities and similarities. So far, there is little data on such accounts, to have a final conclusion, except the obvious characteristics of high motivation and aesthetic sensibility. Observations suggest also that there is a very high correlation between the degree of creativity and the degree of concentration or even obsession of the artist when designing their artwork or draw.

Bateson said: "If there be any basic human characteristic which makes men prone to struggle, it would seem to be this hope of release from tension through total involvement"285. Records and even photographs of the artists shown at work in their workshops in a variety of cultural structures depicts how their specific tension is spreading everywhere, and constitutes an important function for the art creator. Extrapolating this creative effervescence can become contagious even for those who look, and thus includes both the creator of art and the admirer - art receiver. A research study which highlights the subtleties of psychological factors, social, situational and cultural factors in the formation of a West African artist among his community, was conducted by d'Azevedo (1958). In this case, cultural perceptions of the type of personality associated with the role of "artist" results in myths that refer to some "deviant" personalities with artistic concerns, aided by a special relationship with a tutelary spirit known as personal muse. The Spirit is the one who insists on intensity, obsession, which are characteristic of creative activity.

Studies on artists performed in other cultures also suggest such a kind of exception to these types of features, but the artist's personality, being, finally, very diverse. A complicated relationship must exist between cultural structures and personality to determine exactly what kind and under what circumstances are regarded as "normal" and as "deviant". It is assumed that where the artist is expected to be very distant, he will take advantage of freedom from conventions in ways expected and allowed by the community. However, some societies apparently provides the necessary conditions for artistic concentration, being present even in the context of an absolutely normal behavior (Goodale and Koss, 1971). It would seem therefore that in their best aspect artists are most obsessed with their creative efforts, and are therefore people who not always perform other duties, successfully, in society.

${ }^{285}$ Bateson, 1949, p.111 


\section{Psychological functions of art}

The prospect that art is a form of self-expression, does not explain why the artist works so disciplined or why people want to support their efforts (Marinela Rusu, $2015 \mathrm{~b}$ ). Theories that try to address the functions of art raise explanations about how things are when it comes to consumers and producers. From this perspective, a psychological theory of art functions include both social and psychological functions. Such theories differ of sociological explanations, first, by the fact of being expressed in psychological terminology. There are a number of perspectives concerned with the most important psychological factors that can lead to artistic creativity and different interpretations concerning the manner how the psychological needs of individuals connect with the social and cultural styles. However, these different perspectives are largely, a matter of emphasis and are difficult to combine in a general way, if someone is not the ardent disciple of some school of psychology (Marinela Rusu, 2014, 2015c).

The explication of abyssal psychology of any orientation, is that the arts are used to symbolically express what cannot, for some reason, become real or may not be met directly. It may take the shape of Wish-Fulfillment, as Freud interpreted the dreams, where fears can take a dragon form which is killed at last or may take the form of a prince or princess. In this perspective, art will express not only what is repressed, but also that which, for some reason has not been achieved in objective reality. In this way, the artist meets the needs of others, whether their needs are similar to those of the artist. It can thus help creating images that meet these needs in terms of fantasy. And because such expressions become symbols of what is wanted, they tend to be intimately correlated with cultural ideals and even with general human values.

Eventually, which are these needs expressed in art? Are they different from those of some other members of society? Do they express nothing but humane? To name a few: the need for security, the need for love, to appreciate and be appreciated, the need for self-realization and self-actualization (Maslow and Jung), and a personal individuation. But love of harmony, color vibrancy, love of beauty? Art expresses not only the artist's frustration, limited and purely individual; it expresses the disillusionment towards this world, which by its nature, creates frustration. Art is not only the artist's wound transposed in an image but is the deploring for all the suffering that exists anywhere in the world, is a gesture of compassion raised to a universal level, generally and elevated.

The expressed forms, images and symbols may be considered as part of the collective unconscious, sized by similar life experiences specific to a particular human condition or culture, having a similarly themed underground. From this point of view, the study of art is based on symbolism, comprehensible symbols within the analyst's frame of reference. Cultural differences are interpreted in terms of themes, desires, fears and dominant values. One perspective is that the most important motivation is the need for creative craftsmanship and is connected with hostility and aggression, with destruction and remuneration linked to the primordial drama - the parricide - believes Muensterberger. He notes: "We have seen the widespread connection between 
death (often actual murder) and the making of an image. The idea of an 'ancestral image' or the 'ancestral mask' has been recognized by field workers for a long time. There is the obvious and acute relationship between oedipal strivings and the making of these objects. Destruction and creation go hand in hand. Through this interaction of destructive and restituted tendencies, the artist is able to channelize his impulses and gain mastery over his aggression" 286 .

This approach defines art as a male occupation and is applied in arts, especially regarding human figure and different types of phallic symbols. Art also expresses fear of castration, correlated with the quality of envy for procreative women. These observations, made by Donald Tuzin in Papua New Guinea (Arapesh, the Sepik River) are supported by the artifacts found here during his expedition with scientific purposes. In a myth they tell how a woman learn from a spirit to give birth to a child and this spirit came thanks to a message carved by man in the house wall. The researcher notes: ". . the event implicitly arrogates to men the procreative powers of women. Art and ritual are the means by which they accomplish this" 287 .

Controlling male aggression is not reflected anywhere in art. On the contrary, many ceremonies are directly related to hunting success. Art does not work as a substitute for violence. The major problem with these theories is that they fit just for some societies but for others they seem completely inadequate. The fact that they cannot be applied to general socio-cultural conditions make them hard to use and translate for different conditions. There is not necessary to accept the idea of superiority of men in the artistic domain, to identify its psychological side. Corroborating the idea that man - with his creative effort destructive-constructive and women with their creative effort for feeding and growth emphasizes reducing masculine concerns for art to sculpture in wood and stone, and those of women to wool-weaving, basket weaving and making clay pots. Without being a universal division, it can be recognized in many tribal communities that still exist in the world today.

Devereux broadens the Freudian approach adding the cultural change indicator. He argues that art is a special way of communicating, having a superior organization and is always changing. His theory is best expressed in the following statements: "Having demonstrated that art provides a safety valve for the expression of that which is tabooed, we must next seek to define the tabooed subjects that find expression in art. The subjects belong to three main layers:

1) The generally human taboos: incest, in-group murder, etc.

2) The culture specific taboos: sex in puritanical society, avariciousness in Mohave society, cowardice in Plains Indian society, etc.

3) The idiosyncratically (neurotically) tabooed: repressed wishes, etc. It is hardly necessary to add that the nature of idiosyncratically tabooed wishes

\footnotetext{
${ }^{286}$ Muensterberger, 1951, p. 371-389
}

${ }^{287}$ D. Tuzin, 1980 
depends to an appreciable extent also upon the dictates of the individual's cultural milieu"288.

"Dynamically speaking, the anthropologist studying art functions is similar to a genuine student of culture and personality when he investigates:

1) The types of tabooed materials that society views as the 'proper' subject of art.

2) The rules of the game for expressing tabooed impulses -- the subterfuges that enable one to be crude and yet rated as a poet.

3) The technical skills needed for complying with the rules of the artistic game.

4) Changes in the content of the ethnic unconscious and in the rules for changing the forbidden into art.

This manner of investigating art is clearly cultural in scope and yet provides massive information about the psychological climate of the culture: about its central areas of conflict and typical defenses"289. A close view is that art is a kind of catharsis, which helps to release tension built up over time. Art Cubeo use alcohol and drugs to build an intense psychological situation, which, in such a situation could have, indeed, a psychological function of catharsis. Attention is concentrated on a funeral, including dances with masks, with a variety of emotional expressions, ranging from solemn to hilarious, from pain to sexual arousal. In addition, coexist the idea that the sacrifice will bring mutual feeling and rewards from the gods; such elaborate artistic ceremonies, involving human sacrifice, mimicked by sounds, seem to have the same psychological function of catharsis as horror or disasters movies have. Whatever the theoretical explanation we take, it is clear that art, in a way, helps individuals to overcome the trauma of death. Beautiful forms of art were part of the funeral, from the time of Neanderthal man. This problem is greeted everywhere by universal human symbolic solutions in order to meet the mental and aesthetic needs, in ways that release emotions.

The way these events are related to the funeral approaches, it shows many characteristic elements of a community and its life philosophy. For example, Balli community achieve psychological, emotional satisfaction, since participation in creating elaborated patterns - in social, ceremonies or in artistic activity, continues uninterrupted. Building an emotional climax is heavily devalued (Bateson, 1949). A strong emotion is therefore expressed as part of the artistic pattern. And we see this especially, in case of emergency. Whether they are supernatural figures such as witch, as the personification of fear, or features of a comedy character, emotion is shown in its most intense state, even if the whole drama does not reach a climax in triumph or tragedy. From a psychological viewpoint Balli art offers both psychological satisfaction and a model of ordering (harmony) that reassures the individuals, but also a controlled expression of emotion, providing a way to "exhaust" the energy, emotionally. Balli community offered the general terms that favored the emergence of the theory of art as a way of expressing taboo elements in society. While conflicts

\footnotetext{
${ }^{288}$ Devereux, 1961, p. 206

${ }^{289}$ Idem, p. 209
} 
are overcome in everyday life by avoiding or by violence, they are drawn in art aesthetically and they become symbolically important.

Within Navajo ritual which includes the dry painting, art has very different psychological functions. The ceremony is centered on psychological and mental maturity and art at all its levels, including contextual situations involves vitality that is orderly, controlled and harmonized, to help directly the acquisition of health, goodness, beauty and harmony. The expressions of passion and conflict are not found in its manifestations. The only "release" is that from anxiety.

Kardiner et al. (1939) suggested that "secondary institutions", for example, all symbolic forms, including arts and religion, are formed by projections, characteristic for the 'basic personality' of society. These secondary institutions help both in shaping personality. He continued to develop this idea, putting most of the emphasis on socialization. Mead, however, explores the phenomenon in the Balinese population: "These childhood fears and agonies are sharp and poignant; left to fester unexpressed, they might easily lead to maladjustment, to deep unhappiness, and perhaps, in the rare and gifted individual, to some artistic expression. But in Bali they are not left to fester but are given continuous expression in the traditional art forms. At festivals the witch mask is brought out; in the shadow play the same dramas enacted; in the dance forms, in the religious trance, in the children's mimetic play, the fear of the witch is relieved, but never completely exorcised - for, another week, the play goes on with the same spectators, the same actors, so as to give satisfaction to a people whose common childhood experience is being reenacted, to lend contentment to their faces and unrestrained gaiety to their laughter" ${ }^{290}$.

Art can be also a way to exhaust intense sexual energy of men which, for various reasons, rarely can be non-restrictive, directly and completely satisfied. But art forms often stimulates expression rather than replacing it, so that psychological mechanisms are not clear. The entire field of erotic art is only being admitted to a respectable study and we still know too little about how to use its functions, and we don't know exactly the proportion of such themes in different cultures. It is even difficult to define accurately the erotic art as a separate category, due to differences in the degree and kind of nudity, gestures etc. which are considered erotic, arousing in various cultural events. Symbolic interpretation varies greatly, also because in some cultures sexual intercourse symbolizes spiritual wisdom, while the prominent phallus of African figurines, symbolize the ancestors' protection. The best forms of art where intercourse is the subject of art - outside Europe and Asia,- are found among the ceramic works of region Ardean, without knowing the exact interpretation of them. For more subtle relationship between erotic feelings and such qualities as rhythm and color, we only have our subjective impressions.

${ }^{290}$ Margaret Mead, 1935, p. 345 


\section{Artistic problems and psychosocial problems}

An important function of art is entertainment, a way of departing from daily problems and professional life; art is not only an ideal valve but is not threatening us and do not involve any risk (Marinela Rusu, 2015). However, paradoxically, precisely because of this feature, the art can be used to find solutions to real problems, giving them first, an artistically solution. Peckham (1965) provides his psycho-biological theory of the function of art, the same as the game, it is a rehearsal under insured conditions, of how to overcome situations that provoke disorder, which produce incitement, as defined by Berlyne (1966). This position tends to be similar to that of Devereux, namely that art has the function to express and expose social and individual problems.

Kavolis's and Kubler's prospects and other's, who consider that art not only provide beauty and relaxation or just excitement and chaos or an oscillation between these two, but at the same time provide a resolution or solution, can also be viewed as psychological theories. Psychological solutions often provide symbolic or metaphorical statements on the relations that have exciting analogies. This vision of art as innovation appears to be similar to that described by Wallace (1961) in movements of revitalization; instead of a prophet and his vision, we have an artist and his inspiration; in both cases we find a reformulated and a symbolic innovative synthesis.

Vision of art as an ingenious way to solve problems is not too far from Jung's perspective, where the unconscious uses archetypal symbols found throughout the human mind to form individual combinations that have to do with psychological recombination of the person, related to their society. The difference between Freud (1913, 1950) and Jung's (1964) perspectives is that the first interprets the symbolism more fluid, with greater variability of meaning, used more creative by individuals than Jung claims. Bateson's formulation (1949) puts consciousness and subconscious relationship in a larger frame of reference. Art is far from integrating the selective, oral mind, supposed to be analytical with a primitive, intuitive unconscious which is not simply and reductionist, and containing only what is repressed or denied, but includes also the basic biological wisdom, body insights of the race and doesn't cut the self accurately from the universe that surrounds him. Of course, not every work of art do all this, but the artistic process helps in communication at all these levels.

Psychological function of art is not always easy to provide a safe valve but is a process by which is reached the completeness; it is not only an individual journey of self but a search for deeper relationships beyond the prison of self. This idea approaches the vision offered by humanism, through the acquisition of incitement, by the fact of making people feel more alive, art helps in the search for meaning and purpose in life. Psychological functions of art include aesthetic pleasure helping human beings in a certain way; being aware of the tragedy and frustration, pain and death, art makes people feel, however, that life is worth living. Or, as Bateson said in his memorable words, "Art is 
enhancing life"291. Art is a life improvement. The theories on art as a method of problems solving, along with aesthetic function to improve life, is not directly related to whether the solutions they present are good or bad, effective or not. Recent studies have underlined the importance of cognitive analogy of human thinking; thus, art forms can be significant in solving problems. Art forms are not making statements about true and false in the terms of formal logic.

6. Conclusions. One important thing that emerges in intercultural studies on artists, their personality, role and their degree of freedom, about their traditionalism or futurism, is the nature of the relationship between the individual and the society in which artists live, with the cultural elements they encounter in their training and becoming path (M. Rusu, I. Olaru, 2015a). When viewed from this perspective, the assumption that the artist is a romantic rebel becomes a superficial stereotype that refers to primitive artist and expresses, through a minimal knowledge, the traditional group consciousness. Motivation, aesthetic sensitivity and intense preoccupation seem to mark everywhere the artistic personality, and so, individuality is very important from this perspective. Being accepted in preforming a specific role, means to be accepted by the others around, which aims to meet their psycho-social needs.

Art has a psychological function both for the viewer and the artist, or in a different universe of discourse, art has social functions which will performed only if the artist's efforts are supported. Depending on a certain extent by the degree of freedom allowed in using techniques, materials and requests from social norms, the craftsman leaves marks of his own style, of his personality in matters of work he created. Characteristic ways to meet the technical and artistic problems, that observers in the field have found that vary from one individual to another, make their mark in the formal properties of the created object, even if the artist does not sign or mark the object with any specific symbol.

In the free media such as modeling clay and some types of drawing and painting, the artist can also reflect himself, through unconscious body movements. These individual characteristics and innovations in interpretation and recombination of characteristic elements affects the product, so we can speak both of the existence of a personal style, as well as the existence of cultural and regional styles. The artist is himself a symbol of creativity, openness and innovation capacity of a society. His image is a strong one, which impresses and inspires. The artist lives the creation fever and spreading not only the beautiful but the self-knowledge too, contributing to improving and enhancing of our lives.

\section{References}

1. Bascom, W. (1969). Creativity and Style in African Art. New York: Rinehart and Winston

2. Bateson, G. (1949). Ball: The Value System of a Steady State. New York: Ballentine Books

${ }^{291}$ Bateson, 1949, p.314 
3. Berlyne, D. E. (1966). Curiosity and Exploration. Science, 153(3731)

4. Davenport, W.H. (1968). Sculpture of the Easter Solomons. Expedition, 10(2)

5. D'Azevedo, W. L. (1958). A Structural Approach to Esthetics: Toward a Definition of Art III Anthropology. American Anthropologist, 60: 702/714, Bloomington: Indiana U. Press

6. Devereux, G. (1961). Art and Mythology: A General Theory, In Kaplan

7. Dubois, C. (1960). The People of Alor. Cambridge Mass, Harvard University.

8. Freud, S. (1913). The Interpretation of Dreams. New York: Macmillan

9. Freud, S. (1950). Totem and Taboo. New York: Norton

10. Goodale, J.C. \& Koss, J.D. (1971). The Cultural Context of Creativity Among the Tiwi, In Otten

11. Jung, C.G. (1964). Man and His Symbols. Doubleday, Garden City

12. Kardiner, A. \& Linton, R. (1939). The Individual and His Society. New York: Columbia University Press

13. Kavolis, V. (1965). The Value-Orientations Theory of Style. Anthropologica Quarterly, 38(1)

14. Kubler, G. (1962). The Shape of Time: Remarks on the History of Things. New Haven: Yale U Press

15. Mead, M. (1935). Sex and Temperament in Three Primitive Societies, London: Routledge

16. (1940). The Arts in Bali, Yale Review 30: 335-347

17. (1959). Creativity in Cross-Cultural Perspective, Winter, Boston

18. Muensterberger, W. (1951). The Roots of Primitive Art. In Wilbur G. B. (ed.) Psychiatry and Culture: Essays in Honor of Geza, Roheim. New York: John Wiley

19. Peckham, M. (1965). Man's Rage for Chaos: Biology, Behavior, and the Arts. Philadelphia: Chilton Books

20. Rusu, M. (2015a). Principiile morale şi expresia lor în artă - contraste și controverse, co-autor Ioana Olaru, conf. dr. Univ. de Arte "G. Enescu", Iași, în Vol 1, coord. Marinela Rusu,"Etic și estetic", p. 17-32

21. Rusu, M. (2015b). Arta și modelarea culturală a personalităţii. In Popa, D.M. \& Iftimie, N.M. Alteritate și Identitate, (p. 205-212), Iași: Performantica

22. Rusu, M. (2015c). Experiența estetică - Creativitate, ideal și interpretare, în vol. colectiv, coord. C. Tofan și C. Sârbu, "Artă și Tradiție în Europa", Ediția aVI-a, 15 iulie, p. 103-108

23. (2014). Dimensiuni ale dezvoltării conștiinței prin artă, în "Artă și Personalitate", vol. I, coord. M. Rusu, Ed. Ars Longa, Iași, p. 78-112.

24. Spencer, R. F. and J. Jesse et al. (1977). The Native Americans. New York: Harper and Row

25. Thompson, R.F. (1969). Abátàn: A Master Potter of the Egbado Yoruba, Berkeley: California Press

26. Tuzin, D., F. (1980). The Voice of the Tambaran: Truth and Illusion in Ilahita Arapesh Religion. Berkeley: U of California Press

27. Wallace, A. \& Fogelson, R. (1961). Culture and Personality, Biennial Review of Anthropology, 2: 42-78 